\title{
Substance misuse, psychiatric disorder and violent
} and disturbed behaviour ${ }^{\dagger}$

\author{
MICHAEL SOYKA
}

\section{Background Epidemiological studies suggest schizophrenia and substance misuse to be associated with a higher rate of violence and crime.}

\begin{abstract}
Aims The literature was evaluated to assess whether people with schizophrenia who use substances have an increased risk for violence and disturbed behaviour.
\end{abstract}

Method A detailed Medline analysis was performed and relevant studies were reviewed.

Results A large number of studies have linked substance misuse in schizophrenia with male gender, high incidence of homelessness, more pronounced psychotic symptoms, non-adherence with medication, poor prognosis, violence and aggression. The latter has been proved by clinical, epidemiological and longitudinal prospective studies of unselected birth cohorts. The increased risk for aggression and violent acts cannot be interpreted only as a result of poor social integration. Male gender, more severe psychopathology, a primary antisocial personality, repeated intoxications and non-adherence with treatment are important confounding variables.

\section{Conclusion Substance misuse has} been shown consistently to be a significant risk factor for violence and disturbed behaviour. Future research should try to evaluate possible pharmacological and psychosocial treatment approaches.

\section{Declaration of interest None}

\footnotetext{
†See editorial pp. 307-3II, this issue.
}

Epidemiological studies repeatedly have shown elevated rates of violence in people with mental disorder (Swanson et al, 1990; Steuve \& Link, 1997). This is especially true for individuals who had been treated as a psychiatric in-patients when they were adolescents (Kjelsberg \& Dahl, 1998). Violent and aggressive acts committed by psychiatric patients have attracted psychiatric and public attention for a long time. Over the past decades a number of prominent individuals have been attacked or killed by people with a psychosis or other mental disorders, including exBeatle John Lennon, former US president Reagan and the German top politicians Oscar Lafontaine and Wolfgang Schaueble who were both seriously wounded in the early 1990s. Although these cases may be spectacular, violence and aggression displayed by the mentally ill is usually directed against partners or family members, rather than others (Danielson et al, 1998). There is little evidence of an increasing number of violent acts made by patients with psychosis over time (Taylor \& Gunn, 1999), but the literature suggests that patients with major mental disorders have an increased risk for committing such acts compared with the general population (Coid, 1996; Modestin \& Ammann, 1996); this is especially the case for schizophrenia. Wallace et al (1998) reported that $7.2 \%$ of men convicted of homicide had been treated for schizophrenia before, and similar findings of $5-11 \%$ have been found in other studies (Taylor \& Gunn, 1984; Häfner \& Böker, 1992; Eronen et al, 1996a,b). As Wallace et al (1998) stated, this means that the present data indicate that men with schizophrenia have a risk that is $\mathbf{5 - 1 8}$ times higher than that of the general population. This cannot only be attributed to social factors. The increased risk, especially for psychotic illness, is diminished but persists when demographic factors are taken into account (Marzuk, 1996). Psychiatric and forensic research at present tries to identify not only high-risk groups for committing violent acts but also individual variables and symptoms that can be linked to violence and aggression and may be considered for prevention. One of these covariables might be substance use. There is increasing evidence for substance misuse being a major risk factor for violence and disturbed behaviour per se (Pernanen, 1991) but also in individuals with major psychiatric disorders, especially schizophrenia (Soyka et al, 1993; Smith \& Hucker, 1994; Mullen, 1997; Wessely, 1997; Scott et al, 1998). The major studies conducted to elucidate the inter-relationship between substance misuse and major mental disorders will be discussed here.

\section{SUBSTANCE MISUSE IN SCHIZOPHRENIA}

\section{Clinical studies}

The comorbidity of schizophrenia and substance misuse has attracted considerable attention in recent years (Mueser et al, 1992a; Soyka et al, 1993; Smith \& Hucker, 1994). A review of Mueser et al (1990) on 32 studies published so far showed lifetime prevalence estimates of: $12.3-50 \%$ for alcohol misuse and/or dependence; $12.5-35.8 \%$ for cannabis misuse; $11.3-31 \%$ for misuse/ dependence of stimulants; $5.7-15.2 \%$ for hallucinogens; $3.5-11.3 \%$ for sedatives; and $2-9 \%$ for opioids. The latter phenomenon, which is a comparatively low rate of opioid dependence compared with other substances of misuse, has been reported consistently in the literature. More recent studies have shown even higher prevalence estimates for substance misuse in schizophrenia (Cuffel, 1992). High prevalence estimates for substance misuse have been reported not only in North America but also in Europe (Soyka et al, 1993) and Australia, for which Fowler et al (1998) reported six-month and lifetime prevalences of $26.8 \%$ and $59.8 \%$, respectively, for substance use in schizophrenia.

\section{Is substance misuse in schizophrenia increasing?}

It is a matter of debate whether substance abuse in schizophrenia is really increasing over time (Cuffel, 1992). A recent study of Boutros et al (1998) has linked a rapid increase in new admissions with schizophrenia to Connecticut State Hospitals to an increase in drug-related admissions. For first-episode psychosis, prevalence rates 
for substance use were $20-30 \%$ (Strakowski et al, 1993; Hambrecht \& Häfner, 1996). A more recent study on 168 patients with firstepisode psychosis showed that $37 \%$ of the sample met the diagnosis of substance or alcohol misuse. One-year prevalence rates for drug and alcohol misuse were 19.5 and $11.7 \%$, respectively (Cantwell et al, 1999). The study also gave evidence for an increase in diagnosis of substance-related psychotic disorders over time.

\section{Epidemiological findings}

Owing to Berkson's fallacy (Berkson, 1949), prevalence estimates of substance misuse in schizophrenia or other major mental disorders drawn from clinical samples of inpatients may overestimate the real amount of comorbidity of the two disorders. Prevalence estimates for substance misuse in more chronic samples of patients with schizophrenia were higher than those studied in psychiatric university hospitals (Soyka et al, 1993). Epidemiological studies also indicate substance misuse as being a major problem in schizophrenia. Data from the Epidemiologic Catchment Area study (Regier et al, 1990) suggest a four-fold increased risk of substance misuse in schizophrenia and a six-fold increased risk in mania. Apart from antisocial personality disorder these two disorders had the highest comorbidity with substance misuse; this comorbidity was also higher than with anxiety or depressive disorders. Other epidemiological studies also confirm a significant comorbidity of substance use and schizophrenia (Lindquist \& Allebeck, 1989).

\section{Studies in first-episode psychosis and follow-up studies}

Cantwell et al (1999) examined 168 subjects with first-episode psychosis and reported that criteria for drug use, drug misuse or alcohol misuse were met by $37 \%$ of the sample; $8.4 \%$ of the subjects received a primary diagnosis of substancerelated psychotic disorder, which is a significant increase compared with an earlier cohort from the same catchment area. Risk for substance use was highest in young males. Hambrecht \& Häfner (1996) conducted a careful longitudinal study on the chronology of onset of alcohol dependency in schizophrenia and found that alcohol misuse typically preceded the first signs of schizophrenia, but followed the appearance of the first positive symptom. For cannabis, but no other drugs, Andréasson et al
(1987), in a follow-up study on 45570 young men, reported a strong association between cannabis use at conscription to the Swedish Army and later diagnosis of schizophrenia. The relative risk ratio was 6.0 for heavy users and 2.9 when controlled for other psychiatric diagnoses at conscription. Patients had a more rapid onset of schizophrenia and positive symptoms (Andréasson et al, 1987, 1989; Allebeck et al, 1993).

\section{Clinical characteristics of patients with dual-diagnosis schizophrenia}

Patients with schizophrenia and comorbid substance use disorder differ from patients with schizophrenia alone and from other patients with substance use in a number of ways. Patients with dual-diagnosis schizophrenia tend to consume lower quantities of drugs than other psychiatric patients and show less physical symptoms compared with others (for a review, see Mueser et al, 1998). There is overwhelming evidence for these patients to have a very high re-hospitalisation rate. Prognosis is usually poor (Cuffel et al, 1994; DeQuardo et al, 1994; Linszen et al, 1994). Some studies suggest that dual-diagnosis patients have a better premorbid function and less severe negative symptoms compared with other patients (Dixon et al, 1991; Arndt et al, 1992; Serper et al, 1995; Kirkpatrick et al, 1996). Mueser et al (1990) felt that this phenomenon may reflect selection factors whereby more socially oriented patients with schizophrenia are more likely to come into contact with drugs and subsequently develop substance use, but other studies failed to demonstrate clinical differences between dual-diagnosis patients and patients with simple schizophrenia (for a review, see Mueser et al, 1998). Interestingly, Scheller-Gilkey et al (1999), in a recent magnetic resonance imaging study of 176 patients with schizophrenia, reported that in patients with schizophrenia and alcohol or drug misuse the rate of gross brain abnormalities was slightly less than the rate found in patients with schizophrenia alone. These results failed to reach statistical significance, but the authors felt that these findings reflect a trend that is comparable with previous findings suggesting a better premorbid adjustment and less impairment in certain areas in dualdiagnosis patients. Furthermore, SchellerGilkey et al (1999) could not demonstrate more severe symptoms and a poorer outcome in these patients.

Apart from premorbid functioning, there are some demographic and clinical characteristics of dual-diagnosis schizophrenia that have been more or less consistently reported in the literature. The typical features of dual-diagnosis patients are: male, younger, high incidence of homelessness, more positive and less negative symptoms, more affective disturbance, increased suicide rate, more often treatment refractory, non-adherence with medication, higher rates of tardive dyskinesia, higher doses of neuroleptic, higher rates of hospital admission, higher rates of discharge against advice, higher rates of violence (see below), younger age at time of first hospitalisation (for a review, see Scheller-Gilkey et al, 1999). Even so, apart from gender and age these are only general trends and different studies have shown very mixed results. With regard to psychopathological features, higher levels of hallucinations and delusions and less severe symptoms, no differences at all were reported (for a review, see Mueser et al, 1998).

\section{Aetiological models}

A broad number of theories and findings, as reviewed by Mueser et al (1998), have been put forward to explain the comparatively high comorbidity of substance misuse and schizophrenia, including genetic factors, a shared vulnerability to both disorders, the role of antisocial personality disorder, socio-economic status and cognitive functioning, psychosocial risk factors, selfmedication (alleviation of dysphoria, etc.), and others. Mueser et al (1998) concluded that most of the models have not been proved, and stated that antisocial personality disorder may account for some increased comorbidity but otherwise favoured the supersensitivity model, which posits that biological vulnerability of psychiatric disorders results in sensitivity to small amounts of alcohol and drugs, leading to substance use disorders. This supersensitivity model is an elaboration of the stress-vulnerability models proposed for schizophrenia (Liberman et al, 1986). Mueser et al (1998) also indicated pharmacological studies showing that very low doses of amphetamine produced psychotic symptoms in schizophrenia (Janowsky et al, 1973; Lieberman et al, 1987) and proposed two aetiological-based subtypes of dual-diagnosis patients. The 
first type would be linked to antisocial personality and the second to supersensitivity or increased vulnerability. For aggression and violence, the antisocial personality disorder-related type would be of special relevance.

\section{AGGRESSION AND VIOLENCE IN DUAL-DIAGNOSIS PATIENTS}

\section{Clinical data}

A number of data obtained from selected populations suggest that subjects with the comorbidity of schizophrenia and substance use disorder, especially alcohol dependency, have a more than two-fold risk of committing violent crimes than people with simple schizophrenia (Lindquist \& Allebeck, 1989; Swanson et al, 1990; Eronen et al, 1996a). There is quite substantial proof for this assumption. In a subsequent analysis of the data of two large samples of patients with schizophrenia ( $n=447$ and 192, Soyka et al, 1993; Soyka, 1994) it was shown that those with comorbid substance misuse had been convicted significantly more often than the others (40.1\% v. 13.7\%). Rice \& Harris (1995) studied 618 criminal offenders and reported that $26 \%$ of subjects with schizophrenia who misused alcohol were violent offenders, compared with $7 \%$ of subjects with schizophrenia who did not misuse alcohol.

In a recent study Scott et al (1998) reported results of a follow-up study in a community sample of patients with psychosis: 27 people met the criteria for both psychotic illness and a substance use disorder; 65 were psychotic only. Although the severity of aggression and offending among this community sample was low, individuals with a dual diagnosis were significantly more likely to report a history of committing an offence or recent hostile behaviour. Keyworkers were also more likely to report recent aggression in dual-diagnosis patients. Surprisingly, a relatively large proportion of patients in the psychosis-only group reported substance-related offences. This finding might suggest that either the number of dual-diagnosis patients may be underestimated when basically relying on self-reports, or the substance-related offences themselves may not in any case suggest a substance use disorder. This methodological problem deserves more attention in the future.
Swartz et al (1998) examined 331 involuntarily admitted in-patients with severe mental illness (predominantly schizophrenia and other psychotic disorders, $26.9 \%$ bipolar patients and $5.1 \%$ major depression) who were awaiting a period of out-patient commitment: $33.8 \%$ had problems related to alcohol or drugs and $17.8 \%$ of the study group $(n=59)$ had engaged in serious violent acts before admission. In a multivariable model the authors examined a number of risk factors for violent behaviour and found that the combination of substance misuse and problems and medication non-adherence was found to be associated significantly with serious violent behaviour that occurred in the four-month period before hospitalisation after key socio-economic and clinical characteristics were controlled. Other factors were of minor or no importance. Surprisingly, Swartz et al (1998) were unable to find a relationship between serious violent acts and clinical characteristics of diagnosis and score on the Global Assessment of Functioning Scale (Endicott et al, 1976).

An interesting study on violence in 1136 patients with mental disorders discharged from acute psychiatric in-patient facilities (Steadman et al, 1998) showed that there was no significant difference between the prevalence of violence as detected by self-reports and by reports of collateral informants and by police and hospital records by patients without symptoms of substance misuse and by others living in the same neighbourhood. Substance misuse symptoms significantly raised the rate of violence in both the patients and the comparison groups. The study confirmed the finding of substance misuse being a major risk factor for violence in patients with a major mental disorder, especially schizophrenia. However, a possible methodological problem of the Steadman et al study should be mentioned: due to Berkson's bias there might be a tendency for this material to include a preponderance of comorbid patients $(37.6 \%)$, which may account for the high prevalence rates for violence.

\section{Epidemiological studies}

The most robust findings come from epidemiological and case register studies. Lindquist \& Allebeck (1989) in a study on 644 patients with schizophrenia reported a four times higher rate of violent offences among males with schizophrenia compared with the general population. Prevalence rates for substance misuse in violent offenders $(38 \%)$ were significantly higher compared with patients with simple schizophrenia $(16 \%)$.

Wallace et al (1998) examined the psychiatric history of those convicted in Victoria (Australia) between 1993 and 1995 by case linkage to a register listing nearly all contacts with the public psychiatric service, and found that $25 \%$ of offenders had prior psychiatric contact. Personality disorder and substance misuse accounted for much of this relationship, and schizophrenia and affective disorder were also over-represented, particularly those with coexisting substance misuse. Wallace et al (1998) concluded that the increased offending in schizophrenia and affective disorder is modest and often mediated by coexisting substance misuse.

\section{Longitudinal prospective studies of unselected birth cohorts}

Data from longitudinal prospective studies of an unselected birth cohort in Sweden ( $n=15117$; Hodgins, 1992) and Denmark (Hodgins et al, 1996) also suggest substance use to be a major covariable in the violence of patients with schizophrenia. In the Swedish cohort, men with major mental disorders (schizophrenia, major affective disorders, paranoid states, other psychoses) were 2.5 times more likely to commit a crime than other men and four times more likely to commit a violent offence. The relative risk for violence was even higher in women with major mental disorders. Those people with alcohol dependency were also at a greater risk for such acts. In the Danish cohort, men with major mental disorders had a 2.4-4.5 times increased risk and men who also misused alcohol a 4.2-6.7 times increased risk of committing a violent crime compared with healthy individuals.

The most robust findings probably come from a 26-year follow-up study of an unselected birth cohort $(n=11017)$ in Finland (Räsänen et al, 1998). Men who misused alcohol and were diagnosed with schizophrenia were 25.2 times more likely to commit violent crimes than other mentally healthy men. The risk for patients with schizophrenia without alcohol dependency was 3.6 and for other psychoses it was 7.7. None of the patients with schizophrenia who did not misuse alcohol was recidivist ( $>2$ offences), but the risk of committing more crimes among subjects 
with schizophrenia and alcohol dependency was 9.5-fold. One-fifth of male subjects with schizophrenia were already dependent on alcohol $(n=11)$ before the age of 27 years and they were seven times more likely to commit a violent crime than other patients with schizophrenia. The authors pointed out that these findings greatly exceed other figures reported in the literature (Lindquist \& Allebeck, 1989; Swanson et al, 1990; Eronen et al, 1996a).

\section{Reasons for violence}

The reasons for violence and aggression, especially among dual-diagnosis patients, are a matter of debate because male gender, more severe psychopathology, early onset of psychosis, a primary antisocial personality, social class, employment status, poor insight and non-adherence to treatment are possible important confounding variables, among others. Also, Swartz et al (1998), Smith (1989) and Bartels et al (1991) had already demonstrated a significant relationship between medication nonadherence and violent acts. Interestingly, demographic factors have not been found to be reliable in identifying high-risk individuals in clinical practice (Taylor \& Monahan, 1996). Persecutory delusions seem to be of special relevance for violence in schizophrenia (Nestor et al, 1995). Psychostimulants and cocaine especially were found to provoke or worsen psychotic symptomatology (Dixon et al, 1991). Also, a poor neuroleptic response in patients with a history of psychogenetic drug use has been postulated. Junginger et al (1998) stated that although delusional motivation of violence is rare, a moderate risk exists that delusions will motivate violence at some time during the course of a violent patient's illness. The role of intoxication should also be emphasised (Häfner \& Böker, 1992).

\section{DISCUSSION}

\section{Identifying patients at risk}

There is substantial evidence for substance misuse being a major risk factor for violence and aggression in patients with major mental disorder, especially schizophrenia. Even so, it is frequently overlooked or poorly documented. Research should move on now to predominantly longitudinal studies to identify risk factors that could have clinical utility for anticipating violent behaviour (Smith \& Hucker, 1994; Steadman et al, 1998). Antisocial personality traits, the importance of intoxication, exacerbation of psychotic symptoms, social factors and treatment non-adherence may be among them.

The next step will be the development of risk management strategies and the evaluation of treatment in people with dualdiagnosis schizophrenia and violent offenders. As stated above, most authors agree that substance misuse in schizophrenia is associated not only with violence, but also with a number of other problems, including poor treatment adherence, an increased suicide risk and increased rates of hospital admissions and HIV infection.

\section{Treatment perspectives}

\section{Pharmacological interventions}

Possible pharmacotherapeutic approaches in dual-diagnosis schizophrenia have been discussed in detail elsewhere (Soyka, 1996). Key problems are choice of neuroleptic agent and dosage, drug interactions, management of side-effects, possible role of atypical neuroleptics, antidepressant treatment and relapse prevention. Although few studies have been conducted on this topic, any strategy to reduce psychotic relapse and minimise the risk for sideeffects of antipsychotic treatment, including the use of atypical neuroleptics, should be advocated. Alcohol dependency in particular, but also cannabis, were linked to increased rates of tardive dyskinesia. Some authors feel that substance misuse may be explained as a form of self-medication to improve psychopathology (depression, anhedonia, negative symptoms) or to ameliorate the side-effects of neuroleptic treatment. Pharmacological interactions may also be of importance. Serum levels of neuroleptics (fluphenazine) were found to be decreased in those suffering from schizophrenia and alcohol misuse. A relative neuroleptic refractoriness and a cannabisneuroleptic antagonism were postulated. Although the antipsychotic dose given to dual-diagnosis patients did not differ from that used for patients with simple schizophrenia, the topic deserves specific attention (for a review, see Soyka, 1996). Little is known about the effect of new anticraving drugs such as acamprosate or naltrexone in dual-diagnosis schizophrenia but they should be looked at in more detail.

\section{Psychosocial interventions}

In which facilities should patients with dual-diagnosis schizophrenia be treated - more in the psychiatry or the addiction section of psychiatry, or both? Scott et al (1998) suggested strengthening links between general adult and addiction services, or introducing special services for dual-diagnosis patients (Johnson, 1997) may be a possible strategy. A number of both in-patient and and out-patient treatment models for dual-diagnosis schizophrenia have been proposed (Evans \& Sullivan, 1990) but there is little catamnestic evidence for the efficacy of special treatment models. Even so, this is where the future for these patients lies.

\section{REFERENCES}

Allebeck, P., Adamsson, C., Engström, A., et al (1993) Cannabis and schizophrenia: a longitudinal study of cases treated in Stockholm County. Acta Psychiatrica Scandinavica, 88, 21-24.

Andréasson, S., Allebeck, P., Engström, A., et al (1987) Cannabis and schizophrenia: a longitudinal study of Swedish conscripts. Lancet, ii, 1483-1486.

_, _ \& Rydberg, U. (1989) Schizophrenia in users and nonusers of cannabis: a longitudinal study in Stockholm County. Acta Psychiatrica Scandinavia, 79, 505-510.

Arndt, S., Tyrell, G., Flaum, M., et al (1992)

Comorbidity of substance abuse and schizophrenia: the role of pre-morbid adjustment. Psychological Medicine, 22, 379-388.

Bartels, S. S. J., Drake, R. E., Walach, M. A., et al (1991) Characteristic hostility in schizophrenic outpatients. Schizophrenia Bulletin, 17, 163-17|.

Berkson, J. (1949) Limitations of the application of fourfold tables to hospital data. Biological Bulletin, 2, 47-53.

Boutros, M. N., Bowers, M. B. \& Quinlan, D. (1998) Chronological association between increases in drug abuse and psychosis in Connecticut State Hospitals. Journal of Neuropsychiatry and Clinical Neuroscience, 10, 48-54.

Cantwell, R., Brewin, J., Glazebrook, C., et al (1999)

Prevalence of substance misuse in first-episode psychosis. British Journal of Psychiatry, 174, 150-153.

Coid, J.W. (1996) Dangerous patients with mental illness: increased risks warrant new policies, adequate resources, and appropriate legislation. British Medical Journal, 312, 965-966.

Cuffel, B. J. (1992) Prevalence estimates of substance abuse in schizophrenia and their correlates. Journal of Nervous and Mental Disease, 180, 589-592.

, Shumway, M., Chouljian, T. L., et al (1994) A longitudinal study of substance use and community violence in schizophrenia. Journal of Nervous and Mental Disease, I82, 704-708.

Danielson, K. K., Moffit, T. E., Caspi, A., et al (1998) Comorbidity between abuse of and adult and DSM-III$\mathrm{R}$ mental disorders: evidence from an epidemiological study. American Journal of Psychiatry, 155, |3|-133.

DeQuardo, J. R., Carpenter, C. F. \& Tandon, R. (1994) Patterns of substance abuse in schizophrenia: nature and significance. Journal of Psychiatric Research, 28, 267-275.

Dixon, I., Haas, G., Weiden, P. J., et al (1991) Drug abuse in schizophrenic patients: clinical correlates and 
reasons for use. American Journal of Psychiatry, 148 224-230.

Endicott, J., Spitzer, R., Fleiss, J., et al (1976) The global assessment scale: a procedure for measuring overall severity of psychiatric disturbances. Archives of General Psychiatry, 33, 766-77I.

\section{Eronen, M., Tiihonen, J. \& Hakola, P. (1996a)} Schizophrenia and homicidal behaviour. Schizophrenia Bulletin, 22, 83-89.

—, Hakola, P. \& Tiihonen, J. (1996b) Mental disorders and homicidal behaviour in Finland. Archives of General Psychiatry, 53, 497-50l.

Evans, K. \& Sullivan, J. M. (1990) Dual Diagnosis Counseling the Mentally III Substance Abuser. New York: Guilford.

Fowler, I. L., Carr, V. C., Carter, N. T., et al (1998) Patterns of current and lifetime substance use in schizophrenia. Schizophrenia Bulletin, 24, 443-455.

Häfner, H. \& Böker, W. (1992) Crimes of Violence by Mentally Abnormal Offenders. Cambridge: Cambridge University Press.

Hambrecht, M. \& Häfner, H. (1996) Substance abuse and the onset of schizophrenia. Biological Psychiatry, $\mathbf{4 0}$ II55-1163.

Hodgins, S. (1992) Mental disorder, intellectual deficiency, and crime: evidence from a birth cohort. Archives of General Psychiatry, 49, 476-483.

—, Mednick, S. A., Brennan, P. A., et al (1996) Mental disorder and crime: evidence from a Danish cohort. Archives of General Psychiatry, 53, 489-496.

Janowsky, D. S., El.-Yousef, M. K., Davis, J. M., et al (1973) Provocation of schizophrenic symptoms by intravenous administration of methylphenidate. Archives of General Psychiatry, 28, 185-191.

Johnson, S. (1997) Dual diagnosis of severe mental illness and substance misuse: a case for specialist services? British Journal of Psychiatry, I7I, 205-208.

Junginger, J., Parks-Levy, J. \& McGuire, L. (1998) Delusions and symptom-consistent violence. Psychiatric Services, 49, 218-220.

Kirkpatrick, B., Amador, X. F., Flaum, M., et a (1996) The deficit syndrome in the DSM-IV field trial: alcohol and other drug abuse. Schizophrenia Research, 20, 69-77.

Kjelsberg, E. \& Dahl, A. A. (1998) High delinquency, disability and mortality - a register study of former adolescent psychiatric in-patients. Acta Psychiatrica Scandinavica, 98, 34-40.

Liberman, R. P., Mueser, K. T., Wallace, C. J., et a (1986) Training skills in the psychiatrically disabled: learning coping and competence. Schizophrenia Bulletin, |2, 63|-647.

Lieberman, J. A., Kane, J. M. \& Alvir, J. (1987) Provocative tests with psychostimulant drugs in schizophrenia. Psychopharmacology, 91, 4I5-433.

Lindquist, P. \& Allebeck, P. (1989) Schizophrenia and assaultive behavior: the role of alcohol and drug abuse. Acta Psychiatrica Scandinavica, 82, 191-195.

Linszen, D. H., Dingemans, P. M. \& Lenior, M. E. (1994) Cannabis abuse and the course of recent-onset schizophrenic disorders. Archives of General Psychiatry, 51, 273-279.

Marzuk, P. M. (1996) Violence, crime and menta illness: how strong a link? Archives of General Psychiatry, 53, $481-486$

Modestin, J. \& Ammann, R. (1996) Mental disorder and criminality: male schizophrenia. Schizophrenia Bulletin, 22, 69-82.

\section{CLINICAL IMPLICATIONS}

- Schizophrenia consistently has been shown to be associated with an increased risk for substance misuse.

- Dual-diagnosis patients seem to have a poorer clinical outcome compared with others.

- Substance use in people with schizophrenia increases the risk for violence and aggression significantly. This cannot be interpreted only as a result of poorer social integration.

\section{LIMITATIONS}

- Medline and literature analysis only.

- Few longitudinal studies have been performed so far.

- Few psychotherapeutic or psychopharmacological intervention studies have been conducted.

MICHAEL SOYKA, MD, Psychiatric Hospital, University of Munich, Nußbaumstrasse 7, 80336 Munich, Germany

(First received 19 May 1999, final revision 29 November 1999, accepted 7 December 1999)

Mueser, K.T., Yarnold, P. R., Levinson, D. F., et al (1990) Prevalence of substance abuse in schizophrenia: demographic and clinical correlates. Schizophrenia Bulletin, 16, 3I-56.

\section{_, Bellack, A. S. \& Blanchard, J. J. (1992a)} Comorbidity of schizoprehenia and substance abuse implications for treatment. Journal of Consulting and Clinical Psychology, 60, 845-856.

_, Drake, R. E. \& Wallach, M. A. (1998) Dua diagnosis: a review of etiological theories. Addictive Behaviors, 23, 717-734.

Mullen, P. E. (1997) A reassessment of the link betwee mental disorder and violent behavior, and its implications for clinical practice. Australian and $\mathrm{New}$ Zealand Journal of Psychiatry, 3I, 3-11.

Nestor, P. G., Haycock, J., Doiron, S., et al (1995) Lethal violence and psychosis: a clinical profile. Bulletin of American Academy of Psychiatry and the Law, 23, 33I-334.

Pernanen, K. (199I) Alcohol in Human Violence. New York: Guilford Press.

Räsänen, P., Tiihonen J., Isohanni, M., et al (1998) Schizophrenia. alcohol abuse, and violent behavior: 26-year followup study of an unselected birth cohort. Schizophrenia Bulletin, 24, 437-44I.

Regier, D. A., Farmer, M. E., Rae, D. S., et al (1990) Comorbidity of mental disorders with alcohol and other drug abuse: results from the epidemiologic catchment area (ECA) study. Journal of the American Medical Association, 264, 2511-2518.

Rice, M. E. \& Harris, T. (1995) Psychopathy, schizophrenia, alcohol abuse and violent recidivism. International journal of Law and Psychiatry, 18, 333-342.
Scheller-Gilkey, G., Lewine, R. R. J., Caudle, J., et al (1999) Schizophrenia, substance use, and brain morphology. Schizophrenia Research, 35, 113-120.

Scott, H., Johnson, S., Menezes, P., et al (1998) Substance misuse and risk of aggression and offending among the severely mentally ill. British Journal of Psychiatry, I72, 345-350.

Serper, M. R., Alpert, M., Richardson, N. A., et al (1995) Clinical effects of recent cocaine use on patients with acute schizophrenia. American Journal of Psychiatry I52, 1464-1469.

Smith, J. \& Hucker, S. (1994) Schizophrenia and substance abuse. British journal of Psychiatry, 165, 13-21.

Smith, L. D. (1989) Medication refusal and the rehospitalized mentally ill inmate. Hospital Community Psychiatry, 40, 491-496.

Soyka, M. (1994) Substance abuse and dependency as a risk factor for delinquency and violent behavior in schizophrenic patients - how strong is the evidence? Journal of Clinical and Forensic Medicine, I, 3-7.

- (1996) Dual diagnosis in patients with schizophrenia: issues in pharmacological treatment. CNS Drugs, 6 414-425.

_, Albus, M., Finelli, A., et al (1993) Prevalence of alcohol and drug abuse in schizophrenic inpatients. European Archives of Psychiatry and Clinical Neuroscience, 242, 362-372.

Steadman, H. J., Mulvey, E. P., Monahan, J., et a (1998) Violence by people discharged from acute psychiatric inpatient facilities and by others in the same neighborhoods. Archives of General Psychiatry, 55 393-401.

Strakowski, S. M., Tohen, M., Stoll, A. L., et al (1993) Comorbidity in psychosis at first hospitalization. American Journal of Psychiatry, I50, 752-757. 
Steuve, A. \& Link, B. (1997) Violence and psychiatric disorders: results from an epidemiological study in Israel. Psychiatry Quarterly, 68, 327-342.

Swanson, J., Holzer, C., Ganju, V., et al (1990) Violence and psychiatric disorder in the community: evidence from the Epidemiologic Catchment Area surveys. Hospital and Community Psychiatry, 41 $761-770$

Swartz, M. S., Swanson, J.W., Hiday, V. A., et a

(1998) Violence and severe mental illness: the effects of substance abuse and nonadherence to medication. American Journal of Psychiatry, I55, 226-23I.

Taylor, P. J. \& Gunn, J. (1984) Violence and psychosis: I. The risk of violence among psychotic men. British Medical Journal, 288, 1945-1949.

_ \& Monahan, J. (1996) Dangerous patients or dangerous diseases? British Medical Journal, 312, 967-969.
_ \& Gunn, J. (1999) Homicides by people with mental illness: myth and reality. British Journal of Psychiatry, $\mathbf{1 7 4}$ $9-14$

Wallace, C., Mullen, P., Burgess, P., et al (1998) Serious criminal offending and mental disorder. British Journal of Psychiatry, 172, 477-484.

Wessely, S. (1997) The epidemiology of crime, violence and schizophrenia. British Journal of Psychiatry, $\mathbf{1 7 0}$, (suppl. 32), 8-II. 